\title{
¿Proporciona la normativa contable española para organizaciones no gubernamentales el marco conceptual idóneo para la presentación de información económico financiera transparente? ${ }^{1}$ Similitudes y diferencias con la normativa internacional aplicada por las $20 \mathrm{ONG}$ más importantes del mundo ${ }^{2}$
}

\author{
María Begoña Villarroya Lequericaonandia ${ }^{3}$ y Sofía Ramos Sánchez ${ }^{4}$
}

Recibido: 15 de febrero de 2018 / Aceptado: 16 de junio de 2018

Resumen. La importancia de las ONGs ha aumentado últimamente consecuencia de la crisis, pero si su papel es importante, también lo es su transparencia. En concreto, estamos interesados en conocer la "calidad" de su información económico-financiera, tanto a nivel nacional como internacional.

Dentro del ámbito nacional comenzaremos el trabajo examinando el Plan Contable de Entidades sin ánimo de lucro aprobado en 2011 (en adelante, PGCESFL) analizando su marco conceptual, fundamentos, principios y conceptos básicos, cuyo cumplimiento conduce -en un proceso lógico deductivo- al reconocimiento y valoración de los elementos de las cuentas anuales de estas organizaciones en España. Este análisis nos proporcionaría una idea del potencial grado de transparencia de la normativa nacional.

La manera de estudiar la normativa internacional se efectuará desde una perspectiva práctica, es decir, observando los distintos criterios y normas aplicados en sus valoraciones por las ONGs más importantes, conociendo las cuentas anuales que presentan y sus estructuras, así como otra información relevante para los usuarios de esta información. Para ello y tras introducir las 20 ONGs más importantes del mundo, buscaremos su información financiera (sus cuentas anuales) publicada en su website, y conoceremos el mayor o menor grado de transparencia que estas cuentas presentan, indagando en su contenido para tratar de averiguar si recogen alguna información específica para una ONG, sobre sus proyectos, su grado de cumplimiento, etc. efectuándose estudio de los mismos y dando a conocer un esquema de su contenido.

1 Versiones previas de este trabajo fueron presentadas al IV Coloquio Ibérico Internacional de Cooperativismo y Economía Social celebrado en Santiago de Compostela los días 5 y 6 de octubre de 2017 y en el XVI Congreso Internacional de Contabilidade (CICA) celebrado en Aveiro los días 12 y 13 de octubre de 2017. Queremos agradecer las sugerencias que en ambos congresos nos hicieron, así como las aclaraciones que nos fueron solicitadas y que han sido incorporados en este documento. Asimismo, agradecemos las observaciones y comentarios de los revisores de la revista, que igualmente han sido tenidos en cuenta en la redacción final del texto.

2 Selección publicada NGO Advisor que utiliza como criterios base el impacto, la innovación y la sostenibilidad de cada una de ellas.

3 Universidad de Valladolid, España

Dirección de correo electrónico: begovi@eco.uva.es

4 Universidad de Valladolid, España

Dirección de correo electrónico: sramos@efc.uva.es

Revesco. (128) 2018: 212-247 
Comprobaremos para finalizar si en la información exigida en España se observa alguna carencia respecto de la presentada por las ONGs analizadas.

Palabras clave: Calidad de la información contable; Relevancia y fiabilidad; Marco conceptual; ONG; Organizaciones sin ánimo de lucro; Transparencia; Comunicación.

Claves Econlit: L31; M14; M48.

[en] Do Spanish accounting standards for NGOs provide an ideal framework for the presentation of transparent financial report? Similarities and differences with international standars applied by the 20 most important NGOs in the world

\begin{abstract}
The importance of NGOs has increased lately due to the crisis, but if their role is important, their transparency is too. Specifically, we are interested in knowing of the "quality" of their economic and financial information, both nationally and internationally.

Within the national level we will begin this paper making an analysis of the Accounting Plan of NonProfit Entities approved in 2011. We are going to study their conceptual framework, principles and basic concepts, regulation, whose compliance leads to -in a logical deductive process- the recognition and valuation of the elements of the annual accounts of these organizations in Spain. This analysis will give us an idea of the potential level of transparency of the national regulation.

The way to study international standards will be carried out from a perspective more practical, observing the different criteria and norms that have being applied by the most important NGOs. To do this, we are going to introduce the 20 most important NGOs in the world, after that we are going to seek and analyze their annual financial reports published on their website, then, we will know the degree of transparency that these reports present. Also, we are going to inquire into their content to try to find out if they collect some specific information for an NGO: about their projects, their degree of compliance, etc.

Finally, we will check if there is any important aspect that is presented by the analyzed NGOs but is not required to the Spanish NGOs.
\end{abstract}

Keywords: Accounting information quality; Relevance and reliability; Conceptual framework; NGO; Non-Profit Entities; Transparency; Communication.

Sumario. 1. Introducción. 2. El marco conceptual del plan contable de las entidades sin ánimo de lucro VS al del PGC. 3. Las ONGS de la muestra: descripción y análisis de la Información contenida en los estados contables. 4. Consideraciones finales. 5. Referencias bibliográficas.

Cómo citar: Villarroya Lequericaonandia, M.B. y Ramos Sánchez, S. (2018) ¿Proporciona la normativa contable española para organizaciones no gubernamentales el marco conceptual idóneo para la presentación de información económico financiera transparente? Similitudes y diferencias con la normativa internacional aplicada por las 20 ONG más importantes del mundo. REVESCO. Revista de Estudios Cooperativos, Segundo Cuatrimestre, No 128, pp. 212-247. DOI: 10.5209/REVE.60736.

\title{
1. Introducción
}

La importancia de las Organizaciones No Gubernamentales (ONGS en adelante) ha aumentado considerablemente estos últimos años consecuencia de la crisis. Los Gobiernos de numerosos países, incapaces de satisfacer las necesidades de la población, ven como las ONGS responden, en función de sus posibilidades, ante sus problemas específicos, tratando de mitigar las desastrosas consecuencias derivadas de la falta de recursos o por su mala utilización (Villarroya e Inglada, 2014). Los programas de ayuda en las situaciones críticas, ya sean desastres naturales o conflictos bélicos, los de protección del orden, de asistencia médica, los 
de lucha por los derechos de los más desfavorecidos, del cuidado del medioambiente, de ayuda para el desarrollo de los países del tercer mundo, e incluso, a través de distribución de cultura, son en numerosas ocasiones atendidos por ONGS, por lo que su papel es fundamental en muchos países, y no solo en los llamados países en vías de desarrollo.

Pero si el papel de las ONGS es importante, también lo es su transparencia respecto de la rendición de cuentas, ya que para llevar a cabo sus acciones, las ONGS deben conseguir y gestionar fondos, y para ello deberán mostrar una imagen de credibilidad y honestidad y más en la época en la que vivimos, en la que las estafas y fraudes forman parte de nuestro día a día.

Esta transparencia aumentaría cumpliendo, entre otros, con los siguientes comportamientos:

- cuando piden donaciones para ayudar en cualquier causa con la que colaboren, no deberían los fondos obtenidos ser destinadas a otros fines distintos;

- cuando informen de los gastos en los que incurren, deberían separar claramente los relacionados con su misión de otros, es decir sin mezclar los gastos de gestión de la misión con los de "las misiones" de los gestores;

- deberían efectuar las inversiones necesarias evitando activos inútiles y financiarlas de la manera más adecuada en función del mercado en el que estén asentadas;

- cuando las metas inicialmente previstas sean inalcanzables, deberían tener los medios para rápidamente darse cuenta y sustituir dichas metas por otras más factibles, sin malgastar tiempo y dinero en una quimera. Y

- que informen en sus websites de todos estos aspectos de una manera pública, sintetizada y objetiva, en lugar de utilizarla únicamente como un elemento de difusión de su misión, objetivos y fundamentalmente con un uso propagandístico para conseguir más fondos y donaciones.

La transparencia puede relacionarse con el cumplimiento por parte de las ONGS de la Benchmarking Standard, que es una Norma que consolida las principales exigencias establecidas por las instituciones públicas y privadas más renombradas del mundo, y que contiene 101 indicadores objetivamente verificables y proporciona información precisa del nivel de rendición de cuentas, rendimiento y dominio de los riesgos a los que normalmente se enfrenta una ONG, ofrece una serie de recomendaciones para acciones correctivas y preventivas con fines de mejora continua y posiciona las ONGS respecto de la síntesis de resultados obtenidos en el mismo sector de actividad, o región. En este sentido, las auditorías de certificación de SGS (Société Générale de Surveillance) proporcionan una evaluación imparcial del nivel de cumplimiento de una ONG respecto de las mejores prácticas internacionales y establecen un marco para la mejora continua, si bien, conseguir información sobre las ONGS con certificación no es tarea fácil.

Partiendo de esta premisa, el objetivo de este trabajo es averiguar si hay algún tipo de información específica para una ONG o algunos criterios de valoración de algunas transacciones, que deberían haber sido tenidas en cuenta por nuestros legisladores al aprobar el Plan Contable de Entidades sin Fines de Lucro (PGCESFL en adelante) aprobado en 2011, para que la información proporcionada 
por estas entidades fuera más relevante y fiable. Para ello trabajaremos en dos campos, uno teórico analizando el $\mathrm{PGCSFL}^{5}$, y otro más práctico, recogiendo la información financiera de las 20 ONGS más importantes del mundo (sus cuentas anuales) publicada en su website, indagando en su contenido y observando el mayor o menor grado de transparencia que estas cuentas presentan.

Para ello:

- Examinaremos el marco conceptual, fundamentos, principios y conceptos básicos, del PGCESFL cuyo cumplimiento conduce en un proceso lógico deductivo al reconocimiento y valoración de los elementos de las cuentas anuales de estas organizaciones en España,

- Conoceremos las 20 ONGS más importantes del mundo, así como el grado de transparencia que en la rendición de cuentas presentan en su web, para ello se comprobará si en los estados contables presentados hay información específica sobre sus proyectos y su grado de cumplimiento, etc. para lo que se efectuará un estudio de los mismos, dando a conocer un esquema de su contenido. Aunque tenemos claro que los resultados que obtengamos de este análisis sobre la transparencia no se pueden extrapolar a todas las ONGS, fundamentalmente por los distintos niveles de recursos con los que cuentan, sí nos permitirá conocer un poco más el funcionamiento de las grandes ONGS, que además operan y rinden cuentas en distintos países, con distintos sistemas contables

- Para finalizar, comprobaremos si en la información exigida en España se observa alguna carencia respecto de la presentada por las ONGS analizadas.

Las 20 ONGS objeto de análisis (por orden de importancia de mayor a menor) BRAC(Bangladesh Rural Advancement Committee), Médecins Sans Frontières (MSF), Skoll Foundation, Danish Refugee Council(RDC); Ashoka, Mercy Corps, OXFAM (Oxford Committee For Famine Relief), Handicap International, Landesa, Acumen Fund, Save The Children, Cure Violence, Barefoot College, Room To Reed, Apoyo, Once Acre Fund, Grameen Foundation, Ceres, Saude Criança e Islamic Relief Worldwide-, han sido seleccionadas por NGO Advisor en 2016 que basa su evaluación en tres pilares: el impacto, la innovación y el gobierno.

Según se recoge en su página web, con el término "impacto" valoran la producción de una ONG, es decir, cómo transforma la vida de sus beneficiarios. Al evaluar este impacto, no sólo buscan evidencias de que el trabajo de la ONG agrega valor a la comunidad a la que sirve, sino que también se presta atención a cómo la organización demuestra sus esfuerzos a través de la información que presenta. Con el término "innovación" valoran el impulso de una organización para desafiarse a sí mismo y su capacidad para superar creativamente los obstáculos. Este pilar también permite que las organizaciones con métodos más nuevos o más exclusivos, sean recompensados por su trabajo para alterar el statu quo de las

\footnotetext{
Trabajaremos desde un punto de vista teórico, pues en un trabajo práctico llevado a cabo en 2013 basado en la información disponible de la Fundación Lealtad, se comprobó que el cumplimiento de sus obligaciones legales y la claridad en cuanto a la comunicación de información, sobre todo aquella relativa a la obtención de fondos, -fundamentalmente contribuciones y donaciones recibidas- y su destino -grado de consecución de los objetivos previamente planteados-, los gastos en los que se incurre en la gestión,... es satisfactorio para una gran mayoría de las ONGS españolas, (Villarroya e Inglada, 2014).
} 
ONGS. Por último, el término "gobierno" evalúa cómo una organización aplica las buenas prácticas tanto con sus empleados y directores como con partes interesadas ${ }^{6}$. A partir de estos pilares se obtienen 165 criterios que dan lugar a unos pocos indicadores ${ }^{7}$.

\section{El marco conceptual del plan contable de las entidades sin ánimo de lucro VS al del PGC}

En este segundo apartado se pondrán de relieve las pocas diferencias existentes en la información presentada por las entidades no lucrativas respecto de las que persiguen la obtención de beneficio. Esta falta de diferencias es debida a que en la búsqueda de una convergencia tanto a nivel nacional como internacional, una gran parte de la información que toda entidad presenta en sus cuentas anuales, independientemente de su finalidad, es común, no solo en el modelo de presentación, sino también en cuanto a los principios aplicables y los criterios de valoración.

Esta similitud es, en nuestra opinión, un problema y es debido a que la normativa contable en la que se basan, está pensada para las grandes empresas con fin de lucro, por lo parece lógico pensar que hubiera sido más acertado que se hubiera concretado un marco conceptual específico para entidades sin fin de lucro y no unas especificaciones ${ }^{8}$ dentro del marco conceptual común que es lo que tenemos.

Pero este no es un debate nuevo, ya que como recogen Brusca y Martí (2005), es obvio que las entidades no lucrativas presentan un entorno diferente al correspondiente a las entidades lucrativas, lo que ha llevado a plantear si esto debe o no condicionar el modelo contable de estas entidades. Así, tradicionalmente ha existido un debate sobre la conveniencia de aplicar o no las mismas normas contables a las entidades no lucrativas que a las empresas, o si por el contrario existían razones para desarrollar sistemas contables específicos. De manera similar Aliaga (2009) recoge la existencia al respecto de opiniones a favor y en contra, entre los primeros se encuentran Hay y Engstorm (1993), frente a las de Granof (1998) que opina que las organizaciones no lucrativas necesitarían principios y mecanismos de registro distintos. Esta cuestión ha quedado patente a lo largo de varias décadas, y ante la falta de consenso, prácticamente lo que ha existido es una

6 Si bien las noticias de estos últimos días sobre las actividades fraudulentas de alguna de las ONGS analizadas nos invitarían a excluirlas del listado de "las 20 más importantes", no hemos querido seguir ese impulso por dos motivos, el primero es que el listado no ha sido elaborado por nosotras, y el segundo es que, al margen de las actividades denunciadas -que desearíamos que se tratase de unos hechos aislados-, queremos reconocer el papel beneficioso que las ONGS tienen en la sociedad, así como recoger el grave perjuicio que suponen los comportamientos delictivos de algunos de sus directivos o miembros en el conjunto de las ONGS y por tanto en la sociedad a la que protegen y ayudan.

7 Estos indicadores son: Calificación de contratación; Sostenibilidad; Diversidad en las corrientes de financiación; Ratio de innovación; Transparencia y Responsabilidad; Independencia de los gobiernos; Independencia de las corporaciones; Medición del impacto; Resultados de la auditoría e Independencia de una fuente de financiación.

8 O como se recoge en el Real Decreto 1491/2011 introduciendo los desarrollos y precisiones necesarios en función de la naturaleza singular de la actividad desarrollada. 
ausencia de regulación de la información contable de estas entidades hasta hace relativamente pocos años.

Partiendo de la base de que, como recoge Anthony (1978 y 1989) -pionero en este sentido-, las necesidades de información para los usuarios en unas y otras entidades son muy distintas, pudiéndose distinguir cinco clases de usuarios en las entidades no lucrativas: los órganos de gobierno, inversores y acreedores, suministradores de recursos, órganos de supervisión, y por último: socios, electores, contribuyentes, usuarios y el público en general, la satisfacción de estas necesidades de información no se conseguirá con la presentación de unos estados contables basados principalmente en el cálculo de la cifra de resultados.

Basándonos en esta misma razón, somos de la opinión que la elaboración de la información contable debería haber tenido esto en cuenta, en lugar de limitarse a introducir algunas precisiones.

Pero al margen de estas diferencias, es importante que estas entidades cumplan con toda la normativa que les sea de aplicación, y por lo tanto con la normativa contable, porque este hecho redunda en su transparencia y en la imagen que las entidades proyecten sobre la sociedad. En este mismo sentido recoge Medina (2009), que cuando se habla de transparencia de las ONG, no se hace referencia a una propiedad física, sino a la actitud de gestionar información de una determinada manera, afirmando que quizás no es posible explicar todo lo que una ONG hace, pero sí es fundamental explicar lo relevante o lo importante y que la idea de transparencia suele ir acompañada de otro concepto, la rendición de cuentas, que no se trata de un concepto relacionado exclusivamente con la gestión económica o con la contabilidad de una organización, sino, como se podrá observar en este trabajo, con la comunicación a determinados colectivos de qué se hace, cómo se hace, cuánto se gasta y con qué se financia, buscando generar confianza y adhesión.

También Fuentes (2007), Ruiz, Tirado y Morales (2008) o Castelo y Lima (2008), se muestran partidarios de este nuevo concepto de rendición de cuentas más allá de la puramente legalista y recogen que la información contable puede constituir un medio idóneo para informar a los donantes y a la sociedad en su conjunto, atendiendo las demandas sociales de una enorme multiplicidad de partes interesadas, además, teniendo en cuenta que estas entidades trabajan en un sector cada vez más complejo y competitivo, cada día se les exige una mayor responsabilidad en sus actuaciones. Esta mayor responsabilidad y la necesaria credibilidad que ha de rodear todas sus actividades, han de traducirse en una actitud en la que la transparencia sea un valor que inspire cualquier actividad que se realice.

Dicha transparencia comienza con la claridad en la redacción de las cuentas anuales, para que la información suministrada sea comprensible y útil para los aportantes, beneficiarios y otros interesados y además atendiendo a su realidad económica y no a su forma jurídica e incluyendo información relevante y fiable sobre el grado de realización en el ejercicio de las actividades previstas para cumplir con los objetivos de la entidad, la naturaleza de los activos, pasivos y patrimonio neto, el excedente del ejercicio como fruto de las actividades realizadas, y medida de la capacidad de autofinanciación de la entidad y la variación total del patrimonio neto de la entidad como expresión de su viabilidad futura y de la 
capacidad para cumplir con los fines de interés general que se le hayan encomendado.

Por otra parte, toda entidad deberá cumplir con los requisitos de relevancia y fiabilidad.

Se entiende que la información es relevante cuando es útil para la toma de decisiones, es decir, cuando ayuda a evaluar sucesos pasados, presentes o futuros, o bien a confirmar o corregir evaluaciones realizadas anteriormente. En particular, para cumplir con este requisito, las cuentas anuales deben mostrar adecuadamente el grado de cumplimiento de los objetivos fijados para la entidad en el ejercicio, derivados de los fines que persiga con su actividad.

En este sentido, tanto las organizaciones con fines de lucro, como las organizaciones sin fines de lucro elaboran sus cuentas para proporcionar información económico-financiera relevante sobre la entidad, sin embargo, la relevancia difiere entre unas y otras en el contenido y el enfoque, ya que mientras que para las primeras la presentación de la información se centra en la generación de más beneficios, en las organizaciones sin fines de lucro se centran en los programas, la investigación y los servicios prestados por la organización. Es decir, al no perseguir la obtención de unas ganancias para que sean distribuidas entre sus propietarios sino atender las necesidades de la sociedad, para que su información sea relevante, deberá centrarse en proporcionar información sobre el estado de sus actividades, los propósitos de la organización, así como distintos datos relativos al número de personas se han beneficiado de la investigación o los programas y servicios llevados a cabo para ayudar a mejorar la comunidad y proporcionar apoyo a los necesitados y no sobre los beneficios obtenidos.

Por otra parte, la información es fiable cuando está libre de errores materiales y es neutral, es decir, está libre de sesgos, y los usuarios pueden confiar en que es la imagen fiel de lo que pretende representar. Una cualidad derivada de la fiabilidad es la integridad, que se alcanza cuando la información financiera contiene, de forma completa, todos los datos que pueden influir en la toma de decisiones, sin ninguna omisión de información significativa.

Adicionalmente, la información financiera debe cumplir con las cualidades de comparabilidad y claridad. La comparabilidad, que debe extenderse tanto a las cuentas anuales de una entidad no lucrativa en el tiempo, como a las de diferentes entidades en el mismo momento y para el mismo periodo de tiempo, debe permitir contrastar la situación y actividad de las entidades, e implica un tratamiento similar para las transacciones y demás sucesos económicos que se producen en circunstancias parecidas.

Por su parte, la claridad implica que, sobre la base de un razonable conocimiento de las actividades de la entidad, del papel del voluntariado, de los proyectos y programas, la contabilidad y las finanzas, los usuarios de las cuentas anuales, mediante un examen diligente de la información suministrada, puedan formarse juicios que les faciliten la toma de decisiones.

\section{Principios y criterios contables}

Como ya se ha comentado, no hay diferencia entre los principios contables del Plan General Contable (PGC en adelante) y los recogidos para las entidades no lucrativas, de ahí que los criterios de valoración sean prácticamente los mismos con 
la lógica excepción de la inclusión del coste de reposición ${ }^{9}$ como mejor estimación del valor de uso para los activos no generadores de flujos de efectivo en el cálculo de su deterioro.

\section{Las cuentas anuales y sus elementos}

En esta parte se recogerán, con referencia al PGC, algunas de las diferencias destacables incluidas en el PGCESFL.

El Balance o Estado de la Situación busca presentar la riqueza de las entidades, es decir, los recursos con los que cuenta para llevar a cabo sus actividades, dar a conocer el estado de sus deudas, así como la diferencia entre uno y otro. Se compone de: Activos: Bienes, derechos y otros recursos controlados económicamente por la entidad como resultado de sucesos pasados, de los que se espera que la entidad obtenga rendimientos aprovechables en su actividad futura. En particular, se incluyen para las entidades sin fines de lucro, aquellos activos que incorporan un potencial de servicio para los usuarios o beneficiarios de la entidad y que no son, por lo tanto, generadores de flujos de efectivo, sino de flujos económico sociales que benefician a la colectividad. Pasivos: Obligaciones actuales surgidas como resultado de sucesos pasados, para cuya extinción la entidad espera desprenderse de recursos económicos. A estos efectos, se entienden incluidas las provisiones, y Patrimonio neto (o activos netos en el caso de algunas ONG): Constituye la parte residual de los activos de la entidad, una vez deducidos todos sus pasivos. Incluye las aportaciones realizadas en concepto de dotación fundacional o fondo social, ya sea en el momento de su constitución o en otros posteriores, por los fundadores o asociados, que no tengan la consideración de pasivos, así como los excedentes acumulados u otras variaciones que le afecten.

Cuenta de resultados (o de actividades). El principal propósito de un estado de resultados para las entidades con ánimo de lucro es proporcionar información relativa al aumento del valor de la empresa a través de sus actuaciones, lo que tiene un impacto en el precio de las acciones y en cualquier caso en la riqueza de sus propietarios. Por su parte, las organizaciones sin fines de lucro, no persiguen la creación de valor de la organización en sí misma, sino en la medida que sea necesario para el cumplimiento de unos objetivos, fines y misiones.

El modelo de esta cuenta se recoge en un estado en el que se muestran los aumentos y disminuciones en el patrimonio neto originados en el ejercicio y que vendrá dado por la suma entre el excedente del ejercicio, -obtenido como diferencia entre los ingresos y gastos-, los ingresos y gastos directamente imputados al patrimonio neto y los reclasificados al excedente del ejercicio, la diferencia entre las aportaciones y disminuciones a la dotación fundacional o fondo social, así como los ajustes por cambios de criterio o error. Este modelo de cuenta de resultados está ampliado con relación al del PGC, ya que en este se unifica el excedente con los resultados directamente imputados al patrimonio neto y las

9 Se define el coste de reposición, como el importe actual que debería pagarse si se adquiriese un activo con la misma capacidad o potencial de servicio, menos, en su caso, la amortización acumulada calculada sobre la base de tal coste, de forma que refleje el funcionamiento, uso y disfrute ya efectuado del activo, sin perjuicio de considerar también la obsolescencia técnica que pudiera afectarle. 
variaciones del patrimonio neto, con lo que no es necesario que estas entidades presenten además el estado de cambios en el patrimonio neto.

Especial relevancia presenta la memoria ${ }^{10}$ para este tipo de entidades incluyéndose en la misma información relativa al grado de cumplimiento de las actividades previstas por la entidad al inicio del ejercicio, diferenciando los recursos obtenidos y aplicados en cada una de ellas, e identificando el número de beneficiarios o usuarios y los recursos humanos empleados para alcanzar dichos fines. También se incluye en la memoria información sobre los flujos de efectivo, en lugar de presentarse como una cuenta independiente.

Un resumen del contenido de las notas de la memoria, cuando sea significativo, se presenta en la tabla $n^{\circ} 1$ Contenido de la memoria. Detalle de las notas específicas de ESFL, en el que se puede apreciar que se incorporan apartados destinados a facilitar información sobre: Bienes integrantes del patrimonio Histórico, Usuarios y otros deudores de la actividad propia, Beneficiarios y acreedores, Memoria de actividades, Aplicación de elementos patrimoniales a fines propios, Gastos de administración e inventario.

El problema que encontramos es precisamente la escasa utilización de este documento por los usuarios. Nos permitirnos efectuar esta afirmación, porque en un trabajo previo (Villarroya y De Miguel; 2010), se pudo comprobar que, si bien había errores en cualquiera de los documentos que componían las cuentas anuales, eran especialmente significativos en la memoria -sin que hubiéramos podido advertir cualquier tipo de quejas o comentarios por parte de los usuarios de la información allí contenida- lo que nos llevó a suponer que normalmente no eran consultados. Apoya esta idea el hecho de que la mayoría de las bases de datos contables que podemos consultar, no suelen incorporar este tipo de información.

Tabla. 1. Contenido de la memoria. Detalle de las notas específicas de ESFL

\begin{tabular}{|c|c|c|}
\hline Nota & & \\
\hline 1 & Actividad de la entidad & \\
\hline 2 & Bases de presentación de las CC AA & \\
\hline 3 & Excedente del ejercicio & Propuesta de aplicación contable del excedente \\
\hline 4 & Normas de registro y valoración & \\
\hline 5 & Inmovilizado material & \\
\hline 6 & Bienes del patrimonio histórico & $\begin{array}{l}\text { Información sobre movimiento y características, inmuebles } \\
\text { recibidos por legado, cedidos para su uso,.. }\end{array}$ \\
\hline 7 & Inversiones inmobiliarias & \\
\hline 8 & Inmovilizado intangible & \\
\hline 9 & Arrendamientos y otras oper. similares & \\
\hline 10 & Instrumentos financieros & \\
\hline 11 & $\begin{array}{l}\text { Usuarios y otros deudores de la } \\
\text { actividad propia }\end{array}$ & $\begin{array}{l}\text { Movimientos de los usuarios, patrocinadores, afiliados y otros } \\
\text { deudores de la actividad propia de la entidad }\end{array}$ \\
\hline 12 & Beneficiarios acreedores & $\begin{array}{l}\text { Movimientos de los beneficiarios y otros acreedores de la } \\
\text { actividad propia }\end{array}$ \\
\hline
\end{tabular}

10 Nos gustaría recordar que el modelo recoge la información mínima a cumplimentar. 


\begin{tabular}{|c|c|c|}
\hline 13 & Fondos propios & \\
\hline 14 & Existencias & \\
\hline 15 & Moneda extranjera & \\
\hline 16 & Situación fiscal & \\
\hline 17 & Ingresos y gastos & Entre otros desglose de Ayudas monetarias y no monetarias \\
\hline 18 & Provisiones y contingencias & \\
\hline 19 & Información sobre medio ambiente & \\
\hline 20 & Retribuciones a L.P. al personal & \\
\hline 21 & Subvenciones donaciones y legados & \\
\hline 22 & $\begin{array}{l}\text { Fusiones entre entidades no lucrativas } \\
\text { y combinaciones de negocios }\end{array}$ & \\
\hline 23 & Negocios conjuntos & \\
\hline 24 & $\begin{array}{l}\text { Actividad de la entidad. Aplicación de } \\
\text { elementos patrimoniales a fines } \\
\text { propios. Gastos de administración }\end{array}$ & $\begin{array}{l}\text {-Las fundaciones de competencia estatal facilitarán } \\
\text { información, de acuerdo con lo dispuesto en la Ley } 50 / 2002 \\
\text { *Identificación y descripción de las actividades desarrolladas } \\
\text { Recursos humanos empleados } \\
\text { Beneficiarios o usuarios de la actividad } \\
\text { Recursos económicos empleados en la actividad } \\
\text { Objetivos e indicadores de la actividad } \\
\text { *Recursos económicos totales empleados por la entidad } \\
\text { *Recursos económicos totales obtenidos por la entidad } \\
\text { (distinguiendo ingresos y deudas) } \\
\text { *Convenios de colaboración con otras entidades } \\
\text { *Desviaciones entre plan de actuación y datos realizados. } \\
\text {-Las restantes entidades deberán identificar y cuantificar los } \\
\text { fines que persiguen en cada una de las actividades } \\
\text { significativas que realicen, informando sobre los medios con } \\
\text { los que se ha financiado la actividad y que recursos } \\
\text { económicos han sido empleados para su realización. Los } \\
\text { recursos humanos aplicados y el número de beneficiarios o } \\
\text { usuarios } \\
\text {-Aplicación de elementos patrimoniales a fines propios } \\
\text { Los bienes y derechos que formen parte de la dotación } \\
\text { fundacional o fondo social, y aquellos vinculados } \\
\text { directamente al cumplimiento de los fines propios, } \\
\text { El destino de rentas e ingresos a que se refiere la Ley 50/2002, } \\
\text { de Fundaciones, indicando el cumplimiento del destino de } \\
\text { rentas e ingresos y los límites a que venga obligada, de } \\
\text { acuerdo con los criterios establecidos en su normativa } \\
\text { específica (según un modelo que se adjunta) } \\
\text {-Detalle de los gastos de administración }\end{array}$ \\
\hline 25 & $\begin{array}{l}\text { Activos no corrientes mantenidos para } \\
\text { la venta y operaciones interrumpida }\end{array}$ & \\
\hline 26 & Hechos posteriores al cierre & \\
\hline 27 & Operaciones con partes vinculadas & \\
\hline 28 & Otra información & \\
\hline
\end{tabular}




\begin{tabular}{|l|l|l|}
\hline 29 & Información segmentada & \\
\hline 30 & Estado de flujos de efectivo & \\
\hline 31 & Inventario & $\begin{array}{l}\text { Comprenderá los elementos patrimoniales integrantes del } \\
\text { balance de la entidad, distinguiendo los distintos bienes, } \\
\text { derechos, obligaciones y otras partidas que lo componen }\end{array}$ \\
\hline
\end{tabular}

Elaboración propia a partir del PGCESFL

\section{Las ONGS de la muestra: descripción y análisis de la Información contenida en los estados contables}

Como ya hemos mencionado, la importancia que estas organizaciones deberían dar a la rendición pública de cuentas es indiscutible, ya que mejorarían su imagen y reputación, y además ofrecerían mayor seguridad a donantes, testadores o patrocinadores acerca del destino de sus dádivas.

Pero no basta con una información financiera que se limite a la presentación de unas cuentas anuales, además resultaría significativo que estas organizaciones presentasen información específica que acrecentase su transparencia, más aún en estos días en los que las estafas, defraudaciones y otros engaños son una constante entre nuestras noticias. Por otra parte, sería de agradecer que su localización fuera rápida y sencilla.

En concreto dicha información debería recoger datos acerca de los proyectos que llevan a cabo y sus grados de realización, cómo se financian, importancia de las donaciones, gastos correspondientes a la misión y gastos de la administración,...

No obstante, la divulgación de información por parte las ONGS entre unos aspectos y otros, es muy distinta, en este sentido Caba, Gálvez y López (2009), en un trabajo sobre el grado de transparencia on-line de la gestión ética de las ONGS, concluyen que la preocupación de las ONGS por divulgar información sobre las consecuencias financieras o las oportunidades de proyectos es escasa, frente a la disponibilidad de las Cuentas Anuales en la red. Recogen estos autores que la elevada divulgación de algunas de las actividades podría indicar que estas entidades consideran esta información muy relevante para el incremento de su legitimidad; también, que los datos parecen indicar que las ONGS se preocupan por la divulgación de la formación que recibe el personal, y por tanto, su compromiso con las personas que trabajan en la organización; sin embargo, no consideran necesaria la difusión de los beneficios indirectos en la comunidad en la que operan, así como la divulgación de los mecanismos para evitar la corrupción o los conflictos de interés.

Es claro que la transparencia y la rendición de cuentas por parte de las ONGS es una cuestión capital a efectos de la obtención de la legitimidad social y del mantenimiento de la credibilidad como sector, y en este sentido, Aguiló, Saavedra y Longás (2014) reconocen que la progresiva extensión de los sistemas de autoregulación, principalmente basada en las certificaciones de buenas prácticas y códigos éticos o de conducta, deberían ser adoptadas masivamente por las organizaciones de este sector, especialmente aquellas que siendo actualmente 
menos consistentes y/o formalizadas están encaminadas a facilitar información pública con medios tan accesibles y económicos como internet.

Por otra parte, la decisión de realizar conductas fraudulentas y su puesta en práctica, como puede ser falsear la información presentada por las ONGS, está en manos de los responsables de su elaboración y presentación, ya que como afirma Villarroya (2000 y 2001) este comportamiento tiene su origen en la interacción de distintos aspectos internos y externos al individuo, siendo necesarias tres condiciones previas: la percepción del individuo de sus relaciones de intercambio, equidad, adopción de aptitudes solidarias y situación económica; la oportunidad de comisión, el individuo debe percibir que estas oportunidades existen y por último, la valoración de las ventajas que esta conducta le proporciona, frente a los inconvenientes de ser descubierto en los controles que se efectúen, de ser castigado en dicho caso y en la posible pena que le pudiera ser impuesta.

Recoge la Asociación Mundial de Organizaciones No Gubernamentales (WANGO), en su Código de ética y conducta para las ONGS, que del mismo modo en que va creciendo la importancia de las ONGS, va aumentando su responsabilidad; las ONGS tienen la responsabilidad de ser transparentes, honestas, responsables y éticas, deberán proporcionar una información fidedigna y no generar situaciones de manipulación para beneficio personal de sus dirigentes.

Estas afirmaciones son compartidas por muchos autores, entre otros, Ruiz, Tirado y Morales (2008), quienes afirman que a la necesidad de atender las demandas sociales de una enorme multiplicidad de partes interesadas, se une el hecho de que estas entidades trabajan en un sector cada vez más complejo y competitivo, por lo que cada día se les exige una mayor responsabilidad en sus actuaciones. Esta mayor responsabilidad y la necesaria credibilidad que ha de rodear todas sus actividades, han de traducirse en una actitud en la que la transparencia sea un valor que inspire cualquier actividad que se realice.

También Castelo y Lima (2008) se muestran partidarios de este nuevo concepto de rendición de cuentas más allá de la puramente legalista, cuando recogen que la divulgación de actividades según criterios sociales y éticos aumenta la reputación y mejora las relaciones entre la organización y los actores externos a la misma.

Opinión similar recoge Herranz (2007) para quien la comunicación y la transparencia son dos elementos interrelacionados. Recoge este autor que en la medida en la que se cuantifique el alto coste que genera el no ser transparente y también se cuantifique el valor de intangibles como la responsabilidad social, el buen gobierno, la confianza, la marca o la reputación, la gestión de la comunicación para la transparencia será un área prioritaria donde las organizaciones no lucrativas inviertan recursos.

Por su parte Álvarez (2017) presenta un propuesta de aplicación de la ley 19/2013 de 9 de diciembre de transparencia, acceso a la información pública y buen gobierno, en la que reconoce la importancia de presentar información de índole voluntaria para mostrar a la opinión pública no solo la labor que hace, sino cómo se hace y con qué medios, rindiendo cuentas del cumplimiento de objetivos cualitativos y cuantitativos, es decir, proporcionando información sobre la eficacia de la entidad, ampliando el concepto de transparencia más allá de los requerimientos normativos. 
Como ya se ha comentado, en un trabajo previo (Villarroya e Inglada, 2014) con una muestra de ONGS españolas, se observaba como la práctica contable de las ONG analizadas era mayoritariamente correcta en opinión de los auditores, ya que sólo un $14 \%$ de las ONG presentaban salvedades o algún comentario o nota ${ }^{11}$, por lo que en las 20 ONGS objeto de este estudio esperamos encontrarnos una situación similar en el que las cuentas anuales estén acompañadas de un informe con una opinión favorable.

En una línea similar al trabajo mencionado, en este tercer apartado se efectúa una descripción de las 20 ONGS más importantes con la finalidad de conocerlas un poco.

A continuación -tras la obtención de la información contable aportada públicamente por las ONGS en sus websites-, se efectuará su análisis.

En un primer momento y a partir de los distintos datos contenidos en su información contable, obtenidos en una observación exploratoria o no estructurada de sus cuentas anuales, se clasifica y sintetiza, buscando una variabilidad en los datos presentados por estas entidades (tipología de la información presentada) que pudiera resultar de interés para este trabajo.

A partir de dichos resultados, que se presentan simplificados en forma de tabla, se efectúa una interpretación de los mismos buscando patrones de conducta que permitan la agrupación de las entidades en distintas categorías. Después trataremos de encontrar explicación a dichas conductas.

Para finalizar, observamos las diferencias entre la información relevante presentada por las ONGS de la muestra y la que debe ser presentada en España, conociendo si alguna de la información presentada debería haber sido tenida en cuenta por los legisladores españoles.

\subsection{Descripción de las 20 ONGS más importantes}

Como se ha comentado en este subapartado se proporciona información de las ONGS, entre otra, su misión e iniciativas, países en los que opera o los campos de trabajo, para no extendernos en este apartado presentamos, en la página siguiente, la tabla N ${ }^{\circ}$ 2: "Tabla informativa de las 20 ONGS más importantes del mundo", un resumen con esta información ${ }^{12}$.

11 En la mayoría de los informes con salvedades, reconoce el auditor que los errores o las incertidumbres encontradas son por problemas de valoración, entre estos problemas destacan la valoración de las subvenciones -que suelen registrarse siguiendo el criterio de caja- y los problemas en la valoración de activos financieros, en particular por la valoración de sociedades participadas con pérdidas o desequilibrios patrimoniales, y por la dificultad de recuperación de créditos de dudoso cobro o de otras inversiones. Otro aspecto destacable es que en una tercera parte de los informes con salvedades, se refleja una incertidumbre sobre la continuidad por problemas de financiación.

12 Esta información que ha sido obtenida de la website de las ONGS analizadas puede ampliarse en la dirección de la web disponible en la bibliografía. 
Tabla. 2. Tabla informativa de las 20 ONGS más importantes del mundo (en orden de importancia).

\begin{tabular}{|c|c|c|c|c|}
\hline ONG & $\begin{array}{l}\text { Año } \\
\text { fund.(1) }\end{array}$ & $\begin{array}{l}\text { Países en los } \\
\text { que opera (1) }\end{array}$ & Misión u objetivos (1) & $\begin{array}{l}\text { Campos de } \\
\text { actuación (2) }\end{array}$ \\
\hline BRAC & 1972 & $\begin{array}{l}\text { Afghanistan, } \\
\text { Bangladesh, } \\
\text { Liberia, } \\
\text { Myanmar, } \\
\text { Nepal, Pakistan, } \\
\text { The Philippines, } \\
\text { Sierra Leona, } \\
\text { South Sudan, } \\
\text { Tanzania, } \\
\text { Uganda }\end{array}$ & $\begin{array}{l}\text { Capacitar a las personas y comunidades en situaciones de } \\
\text { pobreza, analfabetismo, enfermedades e injusticias sociales. Sus } \\
\text { iniciativas buscan conseguir cambios positivos a gran escala a } \\
\text { través de programas económicos y sociales que permitan a } \\
\text { hombres y mujeres realizar su potencial. }\end{array}$ & $\begin{array}{l}\text { Construcción de } \\
\text { la comunidad, } \\
\text { Economía, } \\
\text { Educación y } \\
\text { Cuestiones de } \\
\text { género y Salud }\end{array}$ \\
\hline MSF & $\begin{array}{l}\text { Paris } \\
1971\end{array}$ & $\begin{array}{l}\text { En 2015, MSF } \\
\text { contaba con } 450 \\
\text { proyectos en } 69 \\
\text { países además } \\
\text { de operaciones } \\
\text { de búsqueda y } \\
\text { rescate. }\end{array}$ & $\begin{array}{l}\text { Independientemente de la raza, la religión, el credo o las } \\
\text { convicciones políticas, prestar asistencia a las poblaciones en } \\
\text { peligro, a las víctimas de catástrofes naturales o provocadas por } \\
\text { el hombre ya las víctimas de conflictos armados. Observar la } \\
\text { neutralidad y la imparcialidad en nombre de la ética médica } \\
\text { universal y el derecho a la asistencia humanitaria, para lograrlo } \\
\text { reclama libertad plena y sin trabas en el ejercicio de sus } \\
\text { funciones. Respetar su código de ética profesional y mantener } \\
\text { una independencia total de todas las potencias políticas, } \\
\text { económicas o religiosas }\end{array}$ & $\begin{array}{l}\text { Emergencias y } \\
\text { crisis y Salud }\end{array}$ \\
\hline SKOLL & 1999 & $\begin{array}{lll}\text { Más de } & 175 \\
\text { países } & & \end{array}$ & $\begin{array}{l}\text { Impulsar un cambio mediante el apoyo a aquellos } \\
\text { emprendedores sociales que reconocen los sistemas que } \\
\text { necesitan cambios y luego avanzan el progreso social mediante } \\
\text { el desarrollo de nuevos modelos de cambio para transformar } \\
\text { nuestro mundo en uno mejor. }\end{array}$ & Economía \\
\hline DRC & 1956 & más de 40 países & $\begin{array}{l}\text { Una de sus principales misiones es el desminado, pero en } \\
\text { consonancia con la tendencia seguida por las principales } \\
\text { organizaciones humanitarias de diversificar cada vez más las } \\
\text { actividades, también trabaja en varios sectores "no tradicionales" } \\
\text { centrados en la recuperación, entre ellos: la vivienda y las } \\
\text { infraestructuras de pequeña escala; La microfinanciación, la } \\
\text { seguridad alimentaria y la rehabilitación agrícola, la legislación y } \\
\text { la información relacionadas con el desplazamiento, la } \\
\text { rehabilitación social y la creación de redes y el desarrollo de } \\
\text { capacidades de las ONG. }\end{array}$ & $\begin{array}{l}\text { Infancia } \\
\text { juventud, } \\
\text { Antiminas, } \\
\text { Emergencia y } \\
\text { crisis, Derechos } \\
\text { humanos y } \\
\begin{array}{l}\text { Ayuda al } \\
\text { refugiado }\end{array}\end{array}$ \\
\hline ASHOKA & 1980 & más de 87 países & $\begin{array}{l}\text { Construir un mundo en el que los problemas no crezcan más } \\
\text { rápido que las soluciones. En esta misión, los Emprendedores } \\
\text { Sociales juegan un papel clave, ya que son personas que no sólo } \\
\text { son capaces de resolver problemas en sus respectivos campos de } \\
\text { acción, sino que también son ejemplos de actuación para el } \\
\text { sector ciudadano. }\end{array}$ & Economía \\
\hline
\end{tabular}




\begin{tabular}{|c|c|c|c|c|}
\hline $\mathrm{MC}$ & 1979 & más de 40 & $\begin{array}{l}\text { Ayuda a las personas a sobrevivir y recuperarse cuando se ha } \\
\text { producido un desastre natural, hay un colapso en la economía o } \\
\text { ha estallado un conflicto y también en aquellos países en los que } \\
\text { existen amenazas crónicas para la paz y el progreso, asociándose } \\
\text { con las comunidades para superar los obstáculos y prosperar }\end{array}$ & $\begin{array}{l}\text { Construcción de } \\
\text { la comunidad, } \\
\text { Emergencia y } \\
\text { crisis y Ayuda } \\
\text { al refugiado }\end{array}$ \\
\hline OXFAM & 1995 & más de 90 países & $\begin{array}{l}\text { Ayudar a encontrar soluciones duraderas a la injusticia de la } \\
\text { pobreza. Forma parte de un movimiento global que aboga por un } \\
\text { cambio que de poder a las personas para crear un futuro seguro, } \\
\text { justo y libre de pobreza. }\end{array}$ & $\begin{array}{l}\text { Economía, } \\
\text { Emergencia y } \\
\text { crisis y Ayuda } \\
\text { al refugiado }\end{array}$ \\
\hline HANDICAP & 1982 & $\begin{array}{lll}\text { cerca } & \text { de } & 60 \\
\text { países } & & \\
& & \end{array}$ & $\begin{array}{l}\text { Organización de ayuda y desarrollo independiente e imparcial } \\
\text { que trabaja en situaciones de pobreza y exclusión, conflictos y } \\
\text { desastres naturales. Trabaja junto a las personas con } \\
\text { discapacidad y las poblaciones vulnerables, actuando y dando } \\
\text { testimonio para responder a sus necesidades esenciales, mejorar } \\
\text { sus condiciones de vida y promover el respeto de su dignidad y } \\
\text { derechos fundamentales. }\end{array}$ & $\begin{array}{l}\text { Antiminas, } \\
\text { Economía, } \\
\text { Salud } \\
\text { Inclusión }\end{array}$ \\
\hline LANDESA & 1981 & $\begin{array}{l}\text { Actualmente } \\
\text { China, India, } \\
\text { Myanmar, Sub- } \\
\text { Saharan Africa } \\
\text { (Ethiopia, } \\
\text { Ghana, Kenya, } \\
\text { Liberia, } \\
\text { Rwanda, } \\
\text { Tanzania, } \\
\text { Uganda) }\end{array}$ & $\begin{array}{l}\text { asegurar los derechos de la tierra a millones de mujeres y } \\
\text { hombres más pobres del mundo para proporcionar oportunidades } \\
\text { y promover la justicia social, para lograrlo Landesa trabaja con } \\
\text { gobiernos y organizaciones locales con el objetivo de extender } \\
\text { los derechos de la tierra a los pobres rurales, promoviendo leyes, } \\
\text { políticas y programas que conlleven cambios transformacionales } \\
\text { a gran escala. }\end{array}$ & $\begin{array}{l}\text { Economía, } \\
\text { Cuestiones de } \\
\text { género, } \\
\text { Derechos } \\
\text { Humanos y } \\
\text { Justicia social }\end{array}$ \\
\hline ACUMEN & 2001 & $\begin{array}{l}\text { Trabaja en } \\
\text { numerosos } \\
\text { países } \\
\text { América Latina } \\
\text { y África y en } \\
\text { india y Pakistán }\end{array}$ & $\begin{array}{l}\text { transformar el mundo de la filantropía, mirando a todos los seres } \\
\text { humanos no como extraños, sino como miembros de una } \\
\text { comunidad única y global donde todos tuvieran la oportunidad } \\
\text { de construir una vida de dignidad. }\end{array}$ & $\begin{array}{l}\text { Economía y } \\
\text { Justicia social }\end{array}$ \\
\hline SCHILDREN & $\begin{array}{l}\text { Londres } \\
1919\end{array}$ & $\begin{array}{l}\text { más de } 120 \\
\text { países }\end{array}$ & $\begin{array}{l}\text { Lograr un mundo en el que cada niño alcance el derecho a la } \\
\text { supervivencia, la protección, el desarrollo y la participación, } \\
\text { consistiendo su misión en inspirar avances en la forma en que el } \\
\text { mundo trata a los niños y lograr un cambio inmediato y duradero } \\
\text { en sus vidas. }\end{array}$ & $\begin{array}{l}\text { Infancia } \\
\text { juventud, } \\
\text { Educación, } \\
\text { Salud } \\
\text { Inclusión }\end{array}$ \\
\hline CURE & $\begin{array}{l}\text { Chicago } \\
2000\end{array}$ & más de 20 países & $\begin{array}{l}\text { Reducir la violencia a nivel mundial mediante el control de } \\
\text { enfermedades y los métodos de cambio de comportamiento. Para } \\
\text { ello tiene como metas cambiar el pensamiento, la política y la } \\
\text { práctica en la medida en que se relaciona con la violencia de tal } \\
\text { manera que se ve principalmente como cuestión de salud. }\end{array}$ & $\begin{array}{l}\text { Antiviolencia, } \\
\text { Infancia } \\
\text { juventud, } \\
\text { Construcción de } \\
\text { la comunidad, } \\
\text { Salud y Paz }\end{array}$ \\
\hline BAREFOOT & 1972 & $\begin{array}{l}\text { India y } 77 \text { países } \\
\text { mas }\end{array}$ & $\begin{array}{l}\text { Conseguir que los campesinos pobres adquieran y compartan } \\
\text { conocimientos prácticos en formatos no alfabetizados y en } \\
\text { situaciones que sean accesibles para ellos y su logística vital, }\end{array}$ & $\begin{array}{l}\text { Construcción de } \\
\text { la comunidad, } \\
\text { Economía, }\end{array}$ \\
\hline
\end{tabular}




\begin{tabular}{|c|c|c|c|c|}
\hline & & & $\begin{array}{l}\text { desmitificando la tecnología y poniéndola en manos de los } \\
\text { propios aldeanos }\end{array}$ & $\begin{array}{l}\text { Educación, } \\
\text { Energía y Salud }\end{array}$ \\
\hline RTOREAD & $\begin{array}{l}\text { Nepal } \\
2000\end{array}$ & $\begin{array}{l}\text { países en vías de } \\
\text { desarrollo }\end{array}$ & $\begin{array}{l}\text { Conseguir un mundo en el que todos los niños tengan una } \\
\text { educación de calidad que les permita alcanzar su pleno potencial } \\
\text { y contribuir a sus comunidades y al mundo. }\end{array}$ & $\begin{array}{l}\text { Infancia } \\
\text { juventud, } \\
\text { Educación } \\
\text { Inclusión }\end{array}$ \\
\hline APOPO & 1997 & $\begin{array}{l}\text { Angola } \\
\text { Afganistán y } \\
\text { Camboya o } \\
\text { Mozambique, } \\
\text { Laos, Tanzania, } \\
\text { Tailandia y } \\
\text { Vietnam }\end{array}$ & $\begin{array}{l}\text { Desarrollar tecnología de detección de minas para proporcionar } \\
\text { soluciones a problemas globales e inspirar un cambio social } \\
\text { positivo. Trabajando con ratas, investiga, desarrolla e } \\
\text { implementa tecnología de detección de minas y también en el } \\
\text { campo de la tuberculosis. }\end{array}$ & $\begin{array}{l}\text { Antiminas } \\
\text { Salud }\end{array}$ \\
\hline $\begin{array}{l}\text { ONCE } \\
\text { ACREE }\end{array}$ & $\begin{array}{l}\text { Kenia } \\
2006\end{array}$ & $\begin{array}{l}\text { Kenya, Rwanda, } \\
\text { Burundi, } \\
\text { Tanzania, } \\
\text { Uganda, } \quad \text { y } \\
\text { Malawi }\end{array}$ & $\begin{array}{l}\text { Conseguir que los agricultores mejoren sus cosechas y salgan de } \\
\text { la pobreza, lo que conllevaría comienzan a producir excedentes } \\
\text { de alimentos para sus vecinos. En definitiva, cuando los } \\
\text { agricultores prosperan, erradican la pobreza y el hambre en sus } \\
\text { comunidades. }\end{array}$ & $\begin{array}{l}\text { Construcción de } \\
\text { la comunidad, } \\
\text { Economía, } \\
\text { Medioambiente, } \\
\text { Inclusión } \\
\text { Nutrición } \\
\text { alimentación }\end{array}$ \\
\hline GRAMEEN & 1997 & $\begin{array}{l}\text { África, América, } \\
\text { Asia y Oriente } \\
\text { Medio }\end{array}$ & $\begin{array}{l}\text { Está comprometida en desarrollar y defender soluciones } \\
\text { innovadoras y sostenibles esforzándose por aprovechar las } \\
\text { oportunidades que ofrece la tecnología, especialmente la } \\
\text { tecnología digital, para acelerar el progreso de sus programas de } \\
\text { lucha contra la pobreza y el hambre }\end{array}$ & $\begin{array}{l}\text { Economía, } \\
\text { Acceso a las } \\
\text { TIC y } \\
\text { Microfinanzas. }\end{array}$ \\
\hline CERES & 1989 & & $\begin{array}{l}\text { Movilizar el liderazgo de los inversores y de los negocios para } \\
\text { construir una economía global próspera y sostenible }\end{array}$ & $\begin{array}{l}\text { Energía, } \\
\text { Medioambiente } \\
\text { y Agua }\end{array}$ \\
\hline SAUDE & 1991 & Brasil & $\begin{array}{l}\text { Promover el bienestar biopsicosocial de los niños y sus familias } \\
\text { que viven por debajo de la línea de pobreza, viendo la salud de } \\
\text { manera integrada y como instrumento de inclusión social. }\end{array}$ & $\begin{array}{l}\text { Infancia y } \\
\text { juventud, } \\
\text { Construcción de } \\
\text { la comunidad, } \\
\text { Educación y } \\
\text { Ley y justicia }\end{array}$ \\
\hline ISLAMIC & $\begin{array}{l}\text { Reino } \\
\text { Unido } \\
1984\end{array}$ & Mas de 40 países & $\begin{array}{l}\text { para proteger a los que viven en zonas de alto riesgo, } \\
\text { centrándonos en la reducción del riesgo de desastres y en la } \\
\text { adaptación al cambio climático. }\end{array}$ & $\begin{array}{l}\text { Infancia } \\
\text { juventud, } \\
\text { Economía, } \\
\text { Emergencia y } \\
\text { crisis, Ayuda al } \\
\text { refugiado y } \\
\text { Justicia social }\end{array}$ \\
\hline
\end{tabular}

Elaboración propia a partir de datos publicados por las ONG en su web (1) y por $N G O$ Advisor (2). 


\subsection{Análisis de la información contable}

Aunque en un principio nuestra idea era efectuar un análisis comparativo entre las cuentas anuales auditadas de las 20 ONGS más importantes obtenidas de su página web, y la información española, basándonos en información del balance, resultados, flujos de efectivo o memoria, esto no ha sido del todo posible, ya que nos hemos encontrado con grandes diferencias en la información proporcionada, algunas inesperadas, como entidades que no proporcionan información contable ${ }^{13}$, otras ya previstas, como efectuar valoraciones y presentar la información siguiendo distintas políticas contables, con diferencias significativas en los modelos de cuentas anuales.

En definitiva, y teniendo en cuenta las limitaciones mencionadas, en este subapartado comenzaremos efectuando un análisis descriptivo de esta información y su clasificación, como ya se ha comentado, los datos se han extraído de los estados con información contable de las ONGS y de las notas (de la memoria), así como otra información sobre fecha de las Cuentas Anuales, su auditoría y auditor ${ }^{14}$.

Precisamente, a partir de estos últimos datos (los del contenido del informe de auditoría) se ha comprobado previamente, si la transparencia en términos de relevancia y fiabilidad alcanza a las Cuentas Anuales, es decir, si está redactada con claridad, es comprensible y útil para los aportantes, beneficiarios y otros interesados, si muestra la imagen fiel del patrimonio, de la situación financiera y de las variaciones originadas en el patrimonio neto durante el ejercicio, así como de la actividad desarrollada, de conformidad con las disposiciones legales, y si incluye información relevante y fiable sobre aspectos específicos.

Después, hemos buscado si entre esta información contable se suministra información adicional y específica de las ONGS, fundamentalmente sobre diversos aspectos de la actividad desarrollada.

Ante la imposibilidad de recoger con detalle la información que estas entidades presentan en formato de texto, se ha optado por recoger un resumen de los resultados de este trabajo en formato de tabla (tabla 3: "Tabla resumen de la información contable presentada por las 20 ONGS en su web") ${ }^{15}$.

En dicha tabla se presenta información en columnas sobre:

El informe de auditoría: distinguiendo entre informe favorable, favorable con algunos comentarios o no disponible.

La segunda columna proporciona información sobre si las entidades presentan o no un Balance de situación (o un estado similar), que como se puede apreciar ha sido presentado por todas las entidades de las que se dispone información.

En las tres columnas siguientes, se recoge si estas entidades proporcionan información sobre la cuenta de resultados y el estado de cambios en el patrimonio neto, cuya presentación puede hacerse de forma conjunta, como en la normativa española o por separado. Destacar que si bien el estado de resultados, con mayor o menor nivel de detalle, ha sido presentado por casi todas las entidades

13 Aunque a estas entidades se les ha solicitado vía e-mail una copia de sus cuentas anuales, no se ha recibido respuesta o remiten a la página web en la que la información disponible no es suficiente.

14 Un resumen de esta información se recoge en el anexo 1.

15 Un enlace a los datos contables utilizados con la información presentada por estas entidades puede encontrarse en la bibliografía. 
(17 de 20) la información sobre el estado de cambios en el patrimonio neto ha sido proporcionada por pocas entidades (únicamente por 6).

Casi la mitad de las ONGS proporcionan información del estado de gastos funcionales y una de ellas en formato de nota las cuentas anuales o memoria en lugar de como un estado independiente.

La siguiente columna recoge información sobre las empresas que presentan un estado de flujos de efectivo (o en su caso el estado de origen y aplicación de fondos) distinguiendo si la información presentada es de flujos de explotación, de inversión y/o de financiación.

Las tres columnas siguientes son relativas a la memoria, en la primera se recoge el número de notas; la siguiente recoge las entidades que proporcionan además de la información puramente contable, información específica propia de las ONGS, así como otra información específica fuera de las cuentas anuales, que puede estar o no auditada. En este sentido hemos podido apreciar como la información contable específica presentada es casi tan variada como las ONGS analizadas, habiendo encontrado información sobre donantes, donantes más significativos, donaciones recibidas, fondos recaudados por evento, proyectos de desarrollo social llevados a cabo, aportaciones a proyectos, programas de microfinanzas, calendario de donaciones, índices sobre el cumplimiento de la misión, independencia financiera, información sobre becas, promesas incondicionales de dar, seguimiento de los fondos donados, seguimiento y evolución de los proyectos llevados a cabo, información sobre países, actividades internacionales, etc.

La penúltima de las columnas proporciona información sobre las políticas contables seguidas en la elaboración de los estados financieros.

Para acabar, la última columna recoge si la entidad presenta información en su website (no solo información contable). Como podemos ver la totalidad de las entidades presenta información en la web, fundamentalmente sobre su misión, objetivos, proyectos, petición de donaciones ... 
Tabla. 3. Tabla resumen de la información contable presentada por las 20 ONG en su web (en orden de importancia).

\begin{tabular}{|c|c|c|c|c|c|c|c|c|c|c|c|}
\hline & $\begin{array}{l}\text { Auditoría } \\
\text { (F/M) }\end{array}$ & $\begin{array}{l}\text { Balance de } \\
\text { situación }\end{array}$ & $\begin{array}{l}\text { Estado de ingresos } \\
\text { y gastos }\end{array}$ & $\begin{array}{l}\text { Estado de ingresos } \\
\text { y gastos + ECPN }\end{array}$ & ECPN & $\begin{array}{l}\text { Estado de gtos } \\
\text { funcionales }\end{array}$ & $\begin{array}{l}\text { Estado de flujo } \\
\text { de efectivo }(E / \mathrm{I} / \mathrm{F})(1)\end{array}$ & $\begin{array}{l}\mathrm{N}^{\circ} \text { NOTAS } \\
\text { en memoria }\end{array}$ & $\begin{array}{l}\text { Notas específicas } \\
\text { y otra info }\end{array}$ & $\begin{array}{l}\text { Políticas } \\
\text { contables }\end{array}$ & $\begin{array}{l}\text { Información } \\
\text { en la web }\end{array}$ \\
\hline BRAC & $\mathrm{F}$ & SI & SI & NO & SI & NOTA 31 & E-I-F & 31 & SI & (2) & SI \\
\hline MSF & F-M & SI & SI & NO & SI & NO & E-I-F & 5 & SI & NIIF & SI \\
\hline SKOLL & $\mathrm{F}$ & SI & SI & NO & NO & NO & E-I & 9 & NO & USA & SI \\
\hline DRC & $\mathrm{F}$ & SI & SI & NO & NO & NO & NO & 12 & SI & Danesa & SI \\
\hline ASHOKA & $\mathrm{F}$ & SI & NO & SI & NO & SI & E-I-F & 14 & SI & USA & SI \\
\hline $\mathrm{MC}$ & $\mathrm{F}$ & SI & NO & SI & NO & SI & E-I-F & 16 & SI & USA & SI \\
\hline OXFAM & $\mathrm{F}$ & SI & SI & NO & NO & NO & E-I & 21 & SI & UK & SI \\
\hline HANDICAP & $\mathrm{F}$ & SI & AMPLIADO & NO & NO & NO & ORIGEN-APLIC & 12 & NO & (3) & SI \\
\hline LANDESA & $\mathrm{F}$ & SI & SI & NO & NO & SI & E-I & 8 & NO & USA & SI \\
\hline ACUMEN & $\mathrm{F}$ & SI & SI & NO & NO & SI & E-I & 14 & SI & USA & SI \\
\hline SCHILDREN & $\mathrm{F}$ & SI & SI & NO & NO & SI & E-I-F & 17 & SI & USA & SI \\
\hline CURE & ND & ND & ND & ND & ND & ND & ND & ND & ND & ND & SI \\
\hline BAREFOOT & ND & SI & SI & ND & ND & ND & ND & ND & S/Becas & ND & SI \\
\hline RTOREAD & $\mathrm{F}$ & SI & SI & NO & NO & SI & E-I & 18 & SI & USA & SI \\
\hline APOPO & ND & SI & SI & ND & ND & ND & ND & ND & NO & ND & SI \\
\hline $\begin{array}{l}\text { ONCE } \\
\text { ACREE }\end{array}$ & ND & ND & ND & ND & ND & ND & ND & ND & ND & ND & SI \\
\hline GRAMEEN & F-M & SI & NO & SI & NO & SI & E-I-F & 16 & SI & USA & SI \\
\hline CERES & $\mathrm{F}$ & SI & SI & NO & NO & SI & E-I & 11 & SI & USA & SI \\
\hline SAUDE & $\mathrm{F}$ & SI & NO & NO & SI & NO & E-I & 15 & SI & BRASIL & SI \\
\hline ISLAMIC & F-M & SI & SI & NO & NO & NO & E-I-F & $\begin{array}{l}28 \quad \text { Muy } \\
\text { Esquemática }\end{array}$ & NO & UK & SI \\
\hline
\end{tabular}


Elaboración propia a partir de datos publicados por las ONG.

ND: no disponible

F: favorable/M: Contiene comentarios

1: Contiene información sobre E/I/F Explotación; inversión financiación

2: Continuidad y coste histórico, valor razonable para inversiones en acciones y participaciones en empresas cotizadas

3: Reglas y métodos contables: el previsto en la junta nacional de asociaciones y bajo los principios de prudencia, independencia de ejercicio y continuidad. 


\subsection{Clasificación de las entidades}

Una vez obtenida y analizada la información anterior hemos podido observar como hay tres grupos diferenciados de entidades:

El primero y más numeroso (BRAC, Médecins Sans Frontières, Danish Refugee Council; Ashoka, Mercy Corps, OXFAM, Acumen Fund, Save The Children, Room To Reed, Grameen Foundation, Ceres, y Saude Criança), proporciona información con mayor o menor detalle sobre lo que hacen, cuánto gastan, como se financian, es decir presentan información contable útil e íntegra, de tal manera que puede influir en la toma de decisiones de sus usuarios externos, lo que nos permite suponer que al menos aparentemente busca la transparencia en todos sus aspectos.

Un segundo grupo, (Skoll foundation, Handicap International y Landesa) que proporciona en su web, información contable que podría ser calificada como "de mínimos", es decir no aporta datos específicos que podrían ayudar a los usuarios de la información contable en la adopción de sus decisiones.

Por último, un tercer grupo (Cure Violence, Barefoot college, APOPO, Once acre Fund e Islamic Relief Worldwide) que no proporcionan información contable o está tan esquematizada que es insuficiente o no resulta útil.

\subsection{Diferencias entre la información relevante presentada por las ONGS de la muestra y la que debe ser presentada en España}

Para finalizar y fundamentalmente a partir de la información contenida en las notas y otros documentos presentados del primero de los grupos, hemos buscado aquellos aspectos que han sido comunicados por las ONGS, y han sido comparados con los exigidos por nuestra normativa nacional, para conocer los puntos de convergencia y divergencia entre unas cuentas y otras.

En este sentido, no hemos encontrado diferencias muy significativas respecto de los "estados básicos" balance, cuenta de resultados o estado de flujos de efectivo (en España incorporado a la memoria), pero si nos ha llamado la atención que muchas de las ONGS presentaran un estado independiente con información sobre los gastos funcionales.

Dicho estado normalmente se representa como una tabla de doble entrada que recoge los gastos por filas y en columnas la distribución del mismo por funciones.

Además, algunas ONG recogen información que nos ha parecido especialmente relevante entre otras, el cálculo de índices sobre la independencia financiera, datos contables centrados en las operaciones o un seguimiento de los fondos donados.

\section{Consideraciones finales}

Tratando de dar respuesta al objetivo perseguido con la realización de este trabajo, que ha sido averiguar si hay algún tipo de información que debería haberse tenido en cuenta al aprobar el PGCESFL, queremos resaltar los siguientes puntos:

En primer lugar comentar que no hay en España diferencias significativas entre el marco conceptual recogido en el PGCESFL y el del PGC, a excepción de que el cumplimiento de los fines no lucrativos exige sustituir las referencias a beneficios o 
rendimientos económicos, por la generación de rendimientos aprovechables en su actividad futura, además de algunos cambios en la presentación de los resultados, de la introducción y/o ampliación en la memoria algunos apartados, así como la incorporación de algunas partidas necesarias como pueden ser los bienes no generadores de flujo de efectivo en el activo que es una partida propia y característica de este tipo de entidades, así como de las empresas públicas.

Es definitiva, la búsqueda de una convergencia con la normativa del PGC ha prevalecido sobre los intereses de estas organizaciones y los de sus usuarios, no habiéndose elaborado un plan cuyo marco conceptual estuviese focalizado en lo realmente relevante para estas instituciones dado por los servicios prestados y el grado de cumplimiento programas.

Por otra parte, la divulgación en la website de la información contable de las ONGS analizadas, aunque por regla general es bastante acertada, no podría calificarse de homogénea ya que varía mucho de unas a otras, tanto en cantidad como en calidad.

Aunque como ya se ha mencionado, no pretendíamos alcanzar unas conclusiones generalizables a la población mundial de ONGS, dado que se trata de las "más importantes", -solo han sido 20 organizaciones, que presentan (o no) sus cuentas anuales siguiendo diferentes modelos de presentación y distintas políticas contables-, sí parece que detrás de esta forma de actuar, está la importancia que los gestores de las mismas dan a la comunicación pública de esta información contable en internet, habiendo unas que consideran la rendición de cuentas como un requisito imprescindible e incluso beneficioso (no desde el punto de vista de los resultados), mientras que para otras, esta presentación pública ${ }^{16}$ tal vez podría conllevar una merma de los recursos, optando por no mostrarlos y ofrecer casi únicamente datos de los objetivos, misión, solicitud de donativos, etc,...

Entre las ONGS cuya rendición de cuentas parece apropiada y con relación al contenido de la memoria española, hemos observado como sí hay algunos aspectos que podrían haber sido tenidos en cuenta por los legisladores, como un estado independiente de gastos funcionales o el establecimiento de unos índices de seguimiento de los proyectos. Si bien, el mayor problema que podemos observar viene de la incorporación de la información específica a la memoria. Consideramos esta solución inapropiada, ya que, aunque la información en cierta manera exista, al incluirla en la memoria pierde transcendencia debido, como ya se ha comentado, al escaso uso que por regla general se hace de este documento.

En sentido contrario, y a pesar del comentario anterior, no podemos olvidarnos que el modelo de la memoria es de mínimos por lo que cualquier ONG interesada en proporcionar información que considere significativa, podría hacerlo.

\section{Referencias bibliográfícas}

ADVISOR NGO (2015) TOP 20: listado de las 20 ONG más importantes del mundo extraído el 17 de marzo de 2017, disponible en: https://www.ngoadvisor.net/.

16 Siempre nos referimos a su presentación en la web, no su elaboración, que damos por sentada, ya que en caso de ausencia de contabilidad, sería mucho más grave. 
Aguiló, M., Saavedra, I. y Longás, J. (2014) Sistemas de autoregulación ética en las organizaciones no gubernamentales (ONG) Pedagogía social. Revista interuniversitaria, $\mathrm{N}^{\mathrm{o}} 24$, pp. 253-279.

Aliaga, J (2009) La información financiera de las entidades sin ánimo de lucro. Una aproximación internacional a su marco conceptual, Contaduría Universidad de Antioquia, $\mathrm{N}^{\circ} 55$, pp. 149-164.

Alvarez, B. (2017) La ley de transparencia y las entidades sin ánimo de lucro. Estudios financieros. Revista de contabilidad y tributación: comentarios y casos prácticos. $\mathrm{N}^{\mathrm{o}}$ 408, pp. 179-204.

Anthony, R. (1978) Financial accounting in nonbusiness organitations. An exploratory study of conceptual issues. Conneticut: Financial Accounting Standars Board.

Anthony, R. (1989) Should busineness and nonbusiness accounting be different?, Boston: Harvard Business School Press.

Brusca, I. y Martí, C. (2005) La Información Financiera de las Entidades No Lucrativas: Una Perspectiva Internacional. Cuadernos aragoneses de economía, № 2, pp. 477-510.

Caba, M.C.; Galvez, M.M. y López, M. (2009) La transparencia de las ONG, rendición de cuentas obligatoria versus voluntaria a través de la web. Contaduría universal de Antioquía. $\mathrm{N}^{\mathrm{o}}$ 54, enero junio.

Castelo, M y Lima, L. (2008) Factors influencing social responsability disclosure by portuguese companies. Journal of business Ethics, № 83, pp. 685-701.

Fuentes, J. (2007) Las organizaciones no lucrativas: necesidades de los usuarios de la información financiera. Revista Española del Tercer sector, $\mathrm{N}^{\circ}$ 6, mayo agosto.

FUNDACIÓN LEALTAD (2013) Código de Buenas Prácticas. Extraído el 4 de mayo de 2013 en:

http://www.fundacionlealtad.org/web/jsp/informateycolaboraong/informateparadonar/pr incipios.jsp.

Granof, M. (1998) Government and non-for-profit accounting. New York: John Wiley and sons.

Hay, L y Engstorm, J (1998) Essentials of accounting for governmental and non-for-profit organizations. Boston Irwin, Homewood.

Herranz, J.M. (2007) La gestión de la comunicación como elemento generador de transparencia en las organizaciones no lucrativas. Ciriec-España. Revista de Economía Pública, Social y Cooperativa, № 57, pp. 5-31.

Medina, J.M. (2009) Transparencia y buen gobierno en las ONGD. Revista Española del tercer sector, $\mathrm{N}^{\circ} 11$, enero-abril, pp. 93-113.

Ruiz, M., Tirado, P. y Morales, A.C. (2008) Transparencia y calidad de la información económico-financiera en las entidades no lucrativas. Un estudio empírico a nivel andaluz. Ciriec-España. Revista de Economía Pública, Social y Cooperativa, No 63, pp. 253-274.

SOCIETE GENERALE DE SURVEILLANCE (2009) Certification Audit Of NonGovernmental Organizations The NGO Benchmarking Standar (Versión 2, October 2009), extraído el 21 de marzo de 2017, disponible en: http://www.sgs.com/en/publicsector/monitoring-services/ngo-benchmarking.

Villarroya, M. B. (2000) Aportación del informe de auditoría a la contabilidad. Actualidad Financiera, Año V, 5, pp. 3-18.

Villarroya, M. B. (2001) Contenido y tipo de opinión de los Informes de Auditoría en empresas industriales y su relación con el entorno general, intermedio y específico. Técnica Contable, № 629, pp. 407-418. 
Villarroya, M.B. y De Miguel, M.C. (2010) El informe de auditoría y su relación con la calidad de la información contable Caso particular de las empresas españolas con valores admitidos a cotización y graves problemas financieros. Técnica contable, Vol. $62, \mathrm{~N}^{\mathrm{o}} 726$, pp. 26-37.

Villarroya, M.B. e Inglada, M.E. (2014) ¿Siguen las ONG españolas los mecanismos voluntarios de accountability? Análisis del seguimiento de un grupo de ONG Españolas de los principios propuestos por la fundación lealtad. REVESCO. Revista de Estudios Cooperativos, Segundo Cuatrimestre, $\quad N^{\circ} 115$, pp. 186-214. DOI: 10.5209/rev_REVE.2014.v115.45275.

WANGO (2005); Código de ética y de conducta para las ONGs de la Asociación de organizaciones no-gubernamentales. Información extraída el 29 de junio de 2013 disponible en: http://www.wango.org/codeofethics.aspx.

\section{DATOS CONTABLES Y OTRA INFORMACIÓN DE LAS ONGS}

Acumen fund: información extraída el 15 de mayo de 2017 disponible en http://acumen.org/wp-content/uploads/2016/08/Acumen-Fund-Inc.-andSubsidiaries-2015-Final-Financial-Statements.pdf http://acumen.org/ http://acumen.org/wp-content/uploads/2017/02/2014-Acumen-Fund-Inc-andSubsidiaries-Financial-Statement.pdf

APOPO: información extraída el 18 de mayo de 2017 disponible en https://www.apopo.org/en/ https://www.apopo.org/en/about/results/annual-reports

ASHOKA: información extraída el 10 de mayo de 2017 disponible en https://www.ashoka.org/atom/3129 https://www.ashoka.org/es

Barefoot College: información extraída el 18 de mayo de 2017 disponible en https://www.barefootcollege.org/ https://www.barefootcollege.org/wp-content/themes/barefootcollege/download/2015-consolidated-balancesheet.pdf

BRAC: información extraída el 8 de mayo de 2017 disponible en http://www.brac.net/ http://www.brac.net/images/reports/BRAC-Audit-Report-2015.pdf https://www.ngoadvisor.net/ong/brac/

CERES: información extraída el 19 de mayo de 2017 disponible en https://www.ceres.org/ https://www.ceres.org/sites/default/files/201704/FY2016\%20Ceres\%2C\%20Inc.\%20$\% 20$ Audited\%20Financial\%20Statements.pdf

Cure violence: información extraída el 15 de mayo de 2017 disponible en http://cureviolence.org/wp-content/uploads/2015/06/Cure-Violence-AnnualReport-2014.pdf http://cureviolence.org/

Danish refugee council: información extraída el 10 de mayo de 2017 disponible en https://drc.dk/ 
https://drc.dk/media/2474704/dfh annual gb 2015 web 210416.pdf

Grameen foundation: información extraída el 19 de mayo de 2017 disponible en http://www.grameenfoundation.org/sites/default/files/Grameen-Foundation-

Financial-Statements-2016.pdf http://www.grameenfoundation.org/

Handicap International: información extraída el 12 de mayo de 2017 disponible en

http://www.handicap-international.org/wp-content/uploads/2016/09/7.2-

Rapport_du_commissaire_aux_comptes_-_exercice_2015.pdf

https://www.ngoadvisor.net/ong/handicap-international/

Islamic Relief Worldwide: información extraída el 19 de mayo de 2017 disponible en

http://www.islamic-relief.org/annual-report-2015/

http://www.islamic-relief.org/

landesa: información extraída el 15 de mayo de 2017 disponible en:

http://www.landesa.org/wp-content/uploads/Audit-Report-

2016.pdfhttp://www.landesa.org/land-foundation-development-

blog/https://www.ngoadvisor.net/ong/landesa/

Medecins sans frontieres: información extraída el 9 de mayo de 2017 disponible en

http://www.msf.org/

http://www.msf.org/en/international-activity-reports

http://www.msf.org/sites/msf.org/files/msf_financial_report_2015_final_0.pdf

Mercy Corps: información extraída el 10 de mayo de 2017 disponible en: https://www.mercycorps.org/home?optimizely x6825985198=1

https://www.mercycorps.org/sites/default/files/MC_2014_AnnualReport.pdf

ONE ACRE FUND: información extraída el 19 de mayo de 2017 disponible en: https://www.oneacrefund.org/uploads/all-

files/One_Acre_Fund_2015_Analysis_Financials.pdf

https://www.oneacrefund.org/

OXFAM: información extraída el 10 de mayo de 2017 disponible en:

https://www.oxfam.org/

https://www.oxfam.org/sites/www.oxfam.org/files/file_attachments/2015-

16_soi_annual_report_financial_statements.pdf

Room To Reed: información extraída el 18 de mayo de 2017 disponible en: https://www.roomtoread.org/

https://www.roomtoread.org/media/150177/2015_audited-financials.pdf

SAUDE CRIANÇA: información extraída el 19 de mayo de 2017 disponible en http://www.saudecrianca.org.br/wp-content/uploads/Saude-da-Crianca-2015WM-

21_07-1.pdf

http://www.saudecrianca.org.br/es/

Save the children: información extraída el 15 de mayo de 2017 disponible en: http://www.savethechildren.org/atf/cf/\{9def2ebe-10ae-432c-9bd0df91d2eba74a \}/SAVE-THE-CHILDREN-AUDITED-FINANCIALS-2015. http://www.savethechildren.org/site/c.8rKLIXMGIpI4E/b.6115947/k.B143/Officia 1_USA_Site.htm

SKOLL foundation: información extraída el 10 de mayo de 2017 disponible en: 
http://skoll.org/about/financials/

http://skoll.org/ 


\section{ANEXO 1: DETALLE DE LA INORMACION CONTABLE PRESENTADA POR LAS 20 ONGS EN ORDEN DE IMPORTANCIA (Fecha de las Cuentas Anuales Informe de Auditoría y Memoria)}

1.- BRAC (Bangladesh Rural Advancemente Committee) (2015, 31 de diciembre Bangladesh)

El informe de auditoría de A. Qasem \& Co es favorable para las cuentas de BRAC (Bangladesh).

1. Introducción

2. Resumen de las políticas contables más significativas (continuidad $\mathrm{y}$ coste histórico, valor razonable para inversiones en acciones y participaciones en empresas cotizadas)

3. Saldos en bancos y efectivo

4. Anticipos, depósitos y pagos a cuenta

5. Inventarios

6. Subvenciones y ayudas y cuentas a cobrar

7. Micro préstamos

8. Préstamos "motocicleta"

9. Inversiones en seguridad

10. Inversiones en empresas vinculadas

11. Propiedad planta y equipo

12. Deudas

13. Sobregiros bancarios

14. Préstamos a plazo

15. Depósitos de ahorro de miembros

16. Subvenciones recibidas

17. Ingresos diferidos

18. Otros pasivos a L.P.

19. Ayudas de donantes

20. Empresas sociales

21. Programa de micro finanzas

22. Proyectos de desarrollo social

23. Resultados de inversiones en empresas vinculadas

24. Intereses de depósitos y cuentas aplazo

25. Aportaciones de BRAC para apoyar los proyectos financiados por donantes

26. Tributos

27. Operaciones en moneda extranjera

28. Instrumentos financieros

29. Calendario de las donaciones recibidas

30. Información financiera segmentada

31. Estados funcional de los gastos

2.- Médicos sin fronteras: MSF (2015, 31 de diciembre)

Sus estados contables presentan la información "combinada" (de las distintas entidades separadas) entre la que se puede encontrar información contable sobre los gastos de programa y de la misión 
El informe de auditoría de Ernst \& Young y KPMG es favorable pero recogen que la agregación se ha efectuado con el propósito de agregar los estados financieros realizados en base a las NIIF,por lo que (recogen en su informe) podría no ser adecuado para otro propósito.

1. Criterios contables: Se sigue el criterio del coste histórico y en la medida de lo posible en los criterios de las NIIF. Los estados financieros han sido preparados y presentados de acuerdo a los principios de devengo, correlación de ingresos y gastos, empresa en funcionamiento, uniformidad y la prudencia.

2. Notas al balance de situación

3. Notas al estado de actividades financieras

4. Niveles de información sectorial: se presentan distintos índices sobre la misión, la independencia financiera, información sobre los ingresos recibidos, gastos por naturaleza, programa y financiación.

5. Otra información: sobre becas, compromisos y garantías fuera del balance, sobre hechos posteriores, sobre el personal empleado, los voluntarios, remuneraciones

También presentan: Finanzas por países: indicando los gastos y el origen de los fondos, así como información sobre el personal

Aunque se separe en su presentación de la que estamos habituados al observar en las CC AA de las empresas, esta ONG elabora y presenta unos estados contables, sin duda ninguna, teniendo en cuenta que los usuarios precisan unos datos contables más centrados en sus operaciones.

Por otra parte, presenta el Informe de Actividad Internacional en el que da detalles de sus actividades en cada país así como información financiera y operativa a nivel mundial y reflexiona sobre los principales retos a los que se enfrenta a lo largo del año.

3.- SKOLL Foundation (2015, 31 de diciembre)

El informe de auditoría de Grant Thornton LLP da una opinión favorable a los estados consolidados

1. La organización

2. Principales políticas contables: Se siguen los principios contables generalmente aceptados en USA

3. Inversiones

4. Los bienes de uso

5. Subvenciones a pagar (donaciones aprobadas)

6. Impuesto federal

7. Operaciones vinculadas

8. Planes de pensiones

9. Hechos posteriores

4.- Danish Refugee Council: RDC (2015, 31 de diciembre)

El informe de auditoría de Ernst \& Young es favorable

Informa de las políticas contables que han sido preparadas siguiendo la normativa danesa

1. Fondos recaudados (por eventos) y utilizados 
2. Ingresos obtenidos y gastos necesarios

3. Donaciones de fondos recibidos y utilizados

4. Asignaciones del gobierno

5. Inmovilizado material

6. Efectivo

7. Fondos propios

8. Provisiones

9. Cuentas a pagar

10. Pasivos contingentes

11. Gastos de personal

12. Operaciones vinculadas

De forma conjunta a la anterior información proporciona un informe sobre las actividades llevadas a cabo, evolución de los fondos los últimos años, información sobre los empleados, gastos de administración, diversa información sobre los proyectos internacionales de ayuda en los que participa y un informe de gestión.

5.- ASHOKA (2015, 31 de agosto)

El informe de auditoría de Cleveland \& Gotliffe es favorable para las cuentas consolidadas de ASHOKA

1. Naturaleza de la organización

2. Principales políticas contables: la preparación y presentación razonable de estos estados financieros consolidados se ha elaborado de acuerdo con los principios de contabilidad generalmente aceptados en los Estados Unidos de América;

3. Valores negociables

4. Restricciones de activos neto (patrimonio neto)

5. Activos netos (patrimonio neto) liberados de las restricciones

6. Fondos de dotación

7. Promesas incondicionales de dar

8. Activos fijos

9. Becas

10. Arrendamientos

11. Compromisos presupuestarios para becas

12. Programas y servicios de apoyo

13. Hechos posteriores

14. Fondos de dotación

En la información contable hay información directamente relacionada con sus proyectos muy desarrollada.

6.- Mercy Corps (2016, 30 de junio)

El informe de auditoría de KPMG LLP es favorable para las cuentas consolidadas de Mercy Corps

1. Organización y propósito

2. Resumen de las principales políticas contables: la preparación y presentación razonable de estos estados financieros consolidados se ha efectuado de acuerdo con los principios de contabilidad generalmente aceptados en los Estados Unidos de América; 
3. Valor razonable de los instrumentos financieros e inversiones

4. Promesas incondicionales de dar

5. Microcréditos

6. Propiedad y equipos

7. Inversiones relacionadas con los programas de la organización

8. Deudas

9. Deudas subsidiarias y subordinadas para las actividades de micro financiación

10. Activos netos restringidos temporalmente

11. Obligaciones por Arrendamientos operativos

12. Compromisos y contingencias

13. Plan de beneficios para los trabajadores

14. Fuentes significativas de ingresos y concentración de riesgo

15. Organismos subsidiarios

16. Hechos posteriores

Presentan además un programa suplementario: balance de situación y cuenta de resultados para un análisis adicional (no auditado)

En la información contable hay información directamente relacionada con sus proyectos muy desarrollada.

7.- OXFAM (Oxford Committee For Famine Relief) (2016, 31 de marzo)

El informe de auditoría de PricewaterhouseCoopers LLP es favorable

1. Políticas contables: la presentación de los estados financieros se basa en las Normas de Contabilidad del Reino Unido (UK GAAP), que comprende IFRS102 "La Norma Internacional de Contabilidad"
2. Donaciones y legados
3. Actividades caritativas
4. Otros ingresos
5. Impuestos
6. Recursos gastados
7. Gastos de personal
8. Gastos de fiducia
9. Activos fijos
10. Deudores
11. Efectivo y equivalentes
12. Acreedores
13. Reconciliación de fondos no restringidos
14. Gasto de fondos no restringidos
15. Fondos restringidos
16. Ingresos de fondos restringidos
17. Ingresos de fondos no restringidos

18. Variación de los ingresos de fondos no restringidos $y$ transferencias

19. Análisis de los activos entre los fondos restringidos y no restringidos

20. Operaciones vinculadas

21. Compromisos asumidos 
De forma conjunta a la anterior información proporciona (1) un informe estratégico sobre los propósitos, visión, logros y las actividades llevadas a cabo, estrategias, recursos humanos, así como otra información tanto de los objetivos alcanzados como nuevas propuestas para los próximos años, (2) otro sobre su estructura, gobierno y administración.

8.- Federation HI (Handicap International) (2015, 31 de diciembre)

El informe de auditoría de Ernst \& Young y otros es favorable para las cuentas consolidadas

Su Cuenta de resultados contiene: el Listado, una evaluación de las contribuciones voluntarias en especie, la presentación de la federación, los hechos significativos, el perímetro de consolidación y las reglas y métodos contables: el previsto en la junta nacional de asociaciones y bajo los principios de prudencia, independencia de ejercicio y continuidad.

1. Estado del inmovilizado

2. Estado de las amortizaciones

3. Estado de las provisiones y depreciaciones

4. Variación de los fondos asociados

5. Variación de las subvenciones de capital

6. Estado de vencimientos de créditos y débitos

7. Detalle de los Ingresos a cobrar (créditos)

8. Detalle de los Gastos a pagar (débitos)

9. Ingresos y gastos diferidos

10. Ingresos y gastos financieros

11. Ingresos y gastos extraordinarios

12. Desglose del efectivo

Además, presenta el seguimiento de los fondos donados y otra cuenta con las donaciones de fondos

9.- Landesa (2016, 30 junio)

El informe de auditoría de PetersonSullivan LLP es favorable para las cuentas consolidadas de Landesa

1. Organización y resumen de las principales políticas contables: la preparación y presentación razonable de estos estados financieros consolidados se ha efectuado de acuerdo con los principios de contabilidad generalmente aceptados en los Estados Unidos de América (importancia de las subvenciones plurianuales registradas según la US GAPP)

2. Subvenciones a cobrar

3. Promesas condicionales de dar

4. Bienes y equipo

5. Activos netos temporalmente restringidos

6. Arrendamientos

7. Planes de pensiones

8. Transacciones con partes relacionadas

10.- Acumen Fund (2015, 31 de diciembre) 
El informe de auditoría de PKF O’Connors Davies LLP es favorable para las cuentas consolidadas

1. Organización y estado tributario

2. Resumen de las principales políticas contables la preparación y presentación razonable de estos estados financieros consolidados se ha efectuado de acuerdo con los principios de contabilidad generalmente aceptados en los Estados Unidos de América

3. Concentración del riesgo de crédito

4. Contribuciones y garantías por cobrar

5. Mediciones del valor razonable

6. Bienes y equipo

7. Préstamos relacionados con programas pendientes de cobro (por programas)

8. Inversiones relacionadas con el programa

9. Cambios en los intereses minoritarios

10. Compromisos de pago

11. Activos netos restringidos temporalmente

12. Contribuciones en especie

13. Planes de pensiones

14. Compromisos y contingencias

También presenta información suplementaria: Balance y cuenta de resultados (actividades) detallando los datos de las filiales y una cuenta de gastos funcional.

En la información contable hay información directamente relacionada con sus proyectos muy desarrollada.

11.- Save The Children (2015, 31 de diciembre)

El informe de auditoría de KPMG LLP es favorable para las cuentas consolidadas

1. Organización y propósito

2. Resumen de las principales políticas contables: la preparación y presentación razonable de estos estados financieros consolidados se ha efectuado de acuerdo con los principios de contabilidad generalmente aceptados en los Estados Unidos de América

3. Inversiones

4. Mediciones de valor razonable

5. Productos básicos y servicios de carga marítima

6. Fondos Dotaciones

7. Aportaciones a cobrar, netas

8. Propiedad planta y equipo, neto

9. Deudas a corto plazo

10. Planes de pensiones

11. Beneficios para los empleados jubilados distintas de las pensiones

12. Activos netos restringidos temporal y restringidos permanentemente

13. Compromisos de arrendamiento

14. Compromisos y contingencias

15. Donantes más significativos y concentración del riesgo de crédito

16. Resumen de las actividades (gastos) del programa por sector y tipo 
17. Hechos posteriores

En la información contable hay información directamente relacionada con sus proyectos muy desarrollada.

\section{2.- Cure Violence}

No disponible. Solicitada la información.

\section{3.- Barefoot College (2015, 31 de marzo)}

No se presenta, entre la información disponible en internet, unos estados contables consolidados auditados, solo un resumen de los mismos y un informe de auditoría sobre la transparencia (de 2010). Solicitada la información.

\section{4.- Room To Reed (2015, 31 de diciembre)}

El informe de auditoría de Grant Thornton es favorable para las cuentas consolidadas de Room to read

1. Organización y naturaleza de las actividades

2. Resumen de las principales políticas contables: la preparación y presentación razonable de estos estados financieros consolidados de acuerdo con los principios de contabilidad generalmente aceptados en los Estados Unidos de América

3. Inventarios

4. Promesas de recibir

5. Concentraciones del riesgo de los activos (efectivos)

6. Activo fijo material

7. Valor razonable de los instrumentos financieros

8. Inversiones

9. Activos netos sujetos a restricciones temporales (por programas)

10. Designación de reservas (provisiones) para llevar a cabo (continuar) proyectos en el futuro

11. Planes de pensiones

12. Compromisos de arrendamiento

13. Contribuciones al consejo de administración

14. Donaciones recibidas en especie

15. Impuestos

16. Línea de crédito

17. Contingencias

18. Hechos posteriores

En la información contable hay información directamente relacionada con sus proyectos muy desarrollada.

\section{5.- APOPO}

No se presenta, entre la información disponible en internet, unos estados contables auditados, solo un miniresumen de los mismos Solicitada la información, esperando nueva respuesta. 


\section{6.- One Acre Fund}

No se presenta, entre la información disponible en internet, unos estados contables auditados, solo algo de información sobre las operaciones de ayuda Solicitada la información.

17.- Grameen Foundation (31 de marzo de 2016)

El informe de auditoría de Gelman, Rosemberg \& Freedman es favorable para las cuentas consolidadas pero en un párrafo de énfasis mencionan la posibilidad de que Grammen India tenga problemas de continuidad, si bien los estados financieros se preparan asumiendo ésta.

1. Resumen de las principales políticas contables e información general: la preparación de estos estados financieros consolidados se ha efectuado de acuerdo con FASB ASC 958 a 810

2. Inversiones

3. Préstamos recibidos

4. Inversiones relacionadas con el programa

5. Línea de crédito

6. Activos netos sujetos a restricciones temporales (por programas)

7. Activos netos liberados de restricciones

8. Compromisos de inversiones en la filial india con problemas financieros

9. Contribuciones en especie

10. Compromisos de arrendamiento

11. Contingencias

12. Planes de pensiones

13. Medición del valor razonable

14. Operaciones vinculadas

15. Devolución de donaciones no utilizadas

16. Hechos posteriores

Además, presenta información suplementaria (no auditada) sobre ingresos y gastos funcionales por países

En la información contable hay información directamente relacionada con sus proyectos muy desarrollada.

18.- CERES (2016, 31 de octubre)

El informe de auditoría de Mayer Holfman \& Mc Cann es favorable para las cuentas consolidadas.

1. Naturaleza de las actividades y principales políticas contables se han presentado sobre la base del devengo y los estados financieros consolidados se han preparado de conformidad a los principios de contabilidad generalmente aceptados en USA

2. Subvenciones a cobrar

3. Otras cuentas a cobrar

4. Propiedades y equipo

5. Línea de crédito

6. Prestaciones de jubilación

7. Arrendamientos operativos 
8. Activos netos no restringidos

9. Activos netos sujetos a restricciones temporales (por programas)

10. Activos netos liberados de restricciones

11. Patrocinios fiscales

También presenta información suplementaria (auditada favorablemente): información de ganancias, ingresos y otros apoyos.

En la información contable hay información directamente relacionada con sus proyectos, muy desarrollada.

19.- SAUDE CRIANÇA (2015, 31 de diciembre)

El informe de auditoría de Wilson JO Morales es favorable para las cuentas individuales y consolidadas.

1. Información general

2. Naturaleza de las actividades y principales políticas contables se han presentado de acuerdo con las prácticas contables adoptadas en Brasil, Incluidas las normas específicas aplicables a las fundaciones y entidades sin ánimo de lucro, en particular Resolución del CFC 1.409 / 12 Entidades SFL y las NBC TG 1000 para PYMES

3. Efectivo y equivalente al efectivo

4. Valores mobiliarios

5. Inmovilizado material

6. Intangible

7. Obligaciones con proyectos incentivados

8. Contingencias

9. Patrimonio neto

10. Donaciones y subvenciones recibidas

11. Costes sanitarios

12. Gastos generales y administrativos y servicios de terceros

13. Resultado financiero neto

14. Coberturas de seguros

15. Otras informaciones (sobre su sede social)

En la información contable hay información directamente relacionada con sus proyectos muy desarrollada.

20.- Islamic Relief Worldwide (IRW) (2015, 31 de diciembre)

El informe de auditoría de Crowe Clark Whitehill LLP es favorable para las cuentas consolidadas de IRW, no así para otros informes complementarios

Notas (muy muy resumidas)

1. Principales políticas contables: las CC AA CC se han preparado de conformidad a los principios de contabilidad generalmente aceptados en el Reino Unido

2. Donaciones y legados

3. Otras actividades comerciales

4. Inversiones

5. Ingresos de las instituciones de caridad y destino

6. Revelación de los donantes y sus donaciones (y destinos)

7. Resultados de filiales comerciales 
8. Costes de administración

9. Remuneración de los fideicomisarios

10. Asignación de los costos de apoyo

11. Ingresos netos

12. Gastos de personal

13. Activos intangibles del grupo y matriz

14. Activos materiales del grupo

15. Activos materiales de la matriz

16. Inversiones

17. Inventarios

18. Deudas

19. Créditos

20. Instrumentos financieros

21. Compromisos

22. Costes de pensiones

23. Análisis de los activos y pasivos representativos de fondos

24. Fondos no restringidos

25. Fondos netos restringidos

26. Dotaciones de fondos

27. Partes relacionadas

28. Hechos posteriores

La información contable se encuentra dentro de la información financiera y está muy resumida, normalmente informa del valor inicial, la variación y valor final. 